\title{
SYNTHESIS, CHARACTERIZATION OF A NOVEL CONJUGATED STRUCTURAL OLIGOMER
}

\author{
DONG AN, ZHIWEN YE*
}

\author{
Department of Chemical Engineering, Nanjing University of Science and Technology, Nanjing 210094 P. R. China
}

\begin{abstract}
An octupolar star-shaped ladder-type oligomer composed of electron deriving from 1,3,5-triazine core end-capped by either an electron donating carbazolemoiety(TA(TL)-Ph(3)-CBZ) have been designed and synthesized to investigate the structure-properties relationship of highly efficient multiphoton absorbing materials. The newly synthesized molecules were characterized by ${ }^{1} \mathrm{H}$ NMR, ${ }^{13} \mathrm{C}$ NMR and mass spectrometry. Linear optical properties of the oligomer were investigated by UV-vis and fluorescence spectrometries, as well as the nonlinear optical properties were characterized by two-photon excited fluorescence (2PEF) measurement.
\end{abstract}

Keywords: Oligomer, TA(TL)-Ph (3)-CBZ, MPA, diphenylamine, ter(p-phenylene.

\section{INTRODUTION}

Multi-photon absorption was first theoretically predicted by Maria Goeppert-Mayer (1906-1972) in her doctoral thesis in 1931. In her hypothesis, it was proposed that simultaneous two-photon absorption may take place in the quantum theory of radiation [1]. The theory was not confirmed until the construction of the first laser in 1960s. Invention of laser allowed the verification of two-photon absorption which is a third order optical process required a strong coherent light via the detection of two-photon-excited fluorescence in a europium doped crystal [2].

Three decades after the invention of laser, investigation of two-photon absorption was enhanced by higher viability of sub-picosecond level pulsed laser and the two-photon fluorescence microscopy by Webb and co-workers. In 1990s, development of femtosecond lasing techniques provided more spaces for in-depth nonlinear optical studies which drawn greater attentions from either chemical or physical scientists [3-5] .

$$
\begin{aligned}
& \text { Type I } A-D \\
& \text { Type II } D-D \quad A-A \\
& D-A-D \quad A-D-A
\end{aligned}
$$

Type III Two-dimensional<smiles>[2H]C([2H])=O</smiles><smiles>COP(C)O</smiles><smiles>COP(C)C</smiles><smiles>[2H]C([2H])([2H])OC</smiles>

Type III

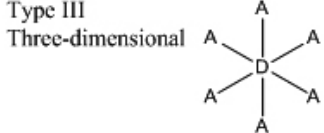<smiles>[2H]C([2H])([2H])[2H]</smiles>

Figure 1. Primary structural motifs of dipolar, quadrupolar and octupolar chromophores where A, D and bridge line represents $\pi$-acceptor( $\pi$-electron deficient), $\pi$-donor ( $\pi$-electron rich) and polarizable $\pi$-bridge respectively.

On early 1990s, the focus on multi-photon studies shifted from purely spectroscopic interests to development new muliti-photon absorption active compounds. Nowadays, numerous principle applications are viable upon the rapid development of multi-photon active compounds, such as, three-dimenstional (3D) imaging [6], 3D optical data storage [7], laser upconversion[8], 3D microfabrication [9], Nonlinear optical transmission, photodynamic threapy. Further studies of multiphoton absorption exhibited by amyloid fibres which are responsible for diseases, such as Alzheimer's and Parkinson's may bring out more inspiration for the therapeutic treatment of these diseases [10].

Essentially, highly efficient multi-photon absorption active compounds composed of three principle components: strong $\pi$-donor, strong $\pi$-donor and connected by polarizable $\pi$-bridge. The molecules possess MPA properties are mainly categorized into three classes (Fig.1) which included: (i) dipolar: A- $\pi$-D; (ii) quadruolar: A- $\pi-\mathrm{A}$; D- $\pi$-D; A- $\pi-\mathrm{D}-\pi-\mathrm{A}$; D-A- $\pi$-D; (iii) octupolar: 3-branched, D-core with $\mathrm{A}$ branch, A-core with $\mathrm{D}$ branch. Multiphoton absorption activities can be commonly observed in these types of compounds that drawing our attention to investigate the structure-properties relationship by either tuning the structure of end capped terminal or the acceptor or donor core [11].

To determine the sensitivity of a $2 \mathrm{PA}$ molecular entity in a quantitative approach, 2PA cross-section $\left(\sigma_{2}\right)$ is employed as a parameter which describes electronic eigenstates as well as transition behavior of a molecule. Thus, the pivotal factor is utilized to evaluate the performance of a $2 \mathrm{PA}$ active molecule. Basically, the greater the value of $2 \mathrm{PA}$ cross-section, the higher of the ability is in preceding the intramolecular charge-transfer[12-14]. Reported by Wong, et al, multi-photon absorption activities are more desirable for the $(\boldsymbol{L})-\mathbf{P h}(\mathbf{n})$ $\mathbf{N P h}$ (with the number of phenyl rings $\mathbf{n}$, ranged from $\mathbf{3}$ to 7 ) with a longer distance of conjugation system showed generally increasing 2PA and 3PA cross-section value. The intramolecular charge transfer would be the main focus on the following experiment on clarifying conjugated system. The MPA activities as electric polarization plays an important role in adjusting the MPA activites (Fig.2).

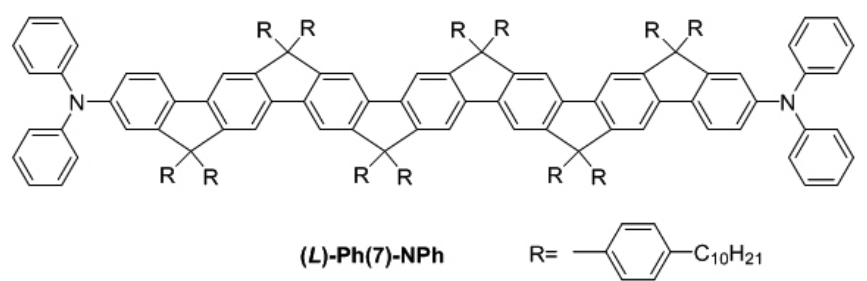

Figure 2. Structure of MPA active organic molecule $(\boldsymbol{L})-\mathbf{P h}(\mathbf{7})-\mathbf{N P h}$

Composed of strong $\pi$-Donor or strong $\pi$-Acceptor, the $\pi$-conjugated system normally has a large transition dipole moment and low excitation value which enhances the 2PA capacities as well as the 2PA cross section [15].

Contributed by many scientists and research groups, numerous Type II and some Type III MPA active compounds were successfully synthesized [16-19] and characterized in the past two decades as investigation of MPA structureproperties relationship. The $\pi$-bridges could be unsaturated aliphatic chains or aromatic ring which connected the acceptor(such as: triazine, triphenylamine) and donors (such as, nitrogen-containing heterocyclic aromatic groups).

Inspired by the previous successful work on synthesizing highly efficient MPA active oligomers by Wong et al, N(TL)-Ph(3)-CBZ and TA(TL)$\mathbf{P h}(3)-\mathbf{N P H}$ have higher potential of further development [20, 21]. In order to continue to investigate the properties of these oligomers, some derivatives can be made to figure out the MPA active oligomers.

Synthesizing weak- $\mathrm{D}_{3}$ D-Core oligomers for the investigation on the relation between structural modifications and its MPA propertie will be a new trail. 
<smiles>[R6]N([R6])[R6]</smiles>

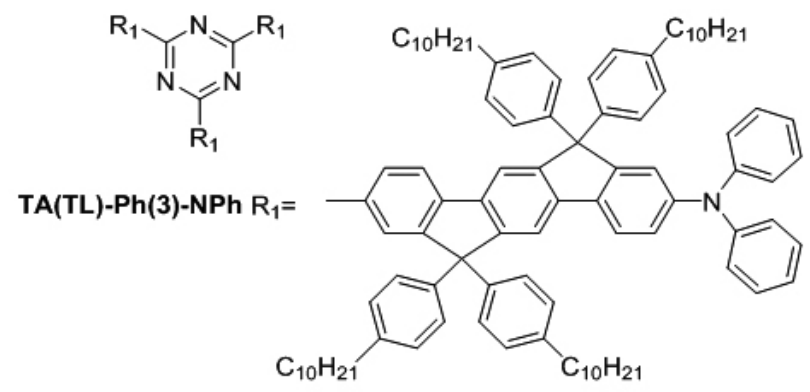

Figure 3. Structures for MPA Active organic molecules.

\section{EXPERIMENTAL}

\section{Materials and apparatus}

All the solvents were dried by the standard methods wherever needed. ${ }^{1} \mathrm{H}$ NMR spectra were produced using either Bruker advanced- III 400 NMR spectrometer with a reference of the residual $\mathrm{CHCl}_{3} 7.26 \mathrm{ppm}$ or DMSO 2.5 ppm. ${ }^{13} \mathrm{C}$ NMR spectra were obtained using Bruker advanced-III 400 NMR spectrometer with a reference of the residual $\mathrm{CHCl}_{3} 77.15 \mathrm{ppm}$ or DMSO $39.5 \mathrm{ppm}$. Mass spectrometer measurements were carried out using fast atom bombardment (FAB) on the API ASTAR Pulsar I Hybrid mass spectrometer or matrix-assisted laser desorption ionization-time-of-flight(MALDI-TOF) technique. Thermal stabilities were determined by thermal gravimetric analyzer (PE-TGA6) with a heating rate of $20^{\circ} \mathrm{C} / \mathrm{min}$ under $\mathrm{N}_{2}$. All the physical measurements were performed in toluene including electronic absorption (UV-Vis) recorded by a Varian Cary UV 100 Scan Spectrophotometer and fluorescence spectra attained by PTI-QM4 Luminescence Spectrophotometer. The fluorescence quantum yields in toluene and chloroform were determined by dilution method using Norharman $\left(\Phi_{330-390}=0.58\right)$ as standard.

Synthesis of TAZ

4-bromobenzonitrile $(4 \mathrm{~g}, 22 \mathrm{mmol})$ in dry chloroform $(60 \mathrm{~mL})$ was added dropwise into a trifluoromethanesulfonic acid $(4 \mathrm{~mL}, 44 \mathrm{mmol})$ in dry chloroform $(10 \mathrm{~mL})$ containing two necked round bottom flask with stirring at $0^{\circ} \mathrm{C}$ under nitrogen gas protection. Heat was given out upon the addition of4-bromobezonitrile. The reaction mixture was stirred for 2 hours at $0^{\circ} \mathrm{C}$ and continued to stir for 48 hours under ambient temperature and nitrogen gas protection. It was neutralized by adding small amount of ammonium hydroxide dropwise in water. The organic layer was washed with water for three times and then dried over anhydrous sodium sulphate. Solvent was removed in vacuo. The residual was recrystallized from $\mathrm{CH}_{3} \mathrm{Cl}$ to obtain a white powder $3.2 \mathrm{~g}$ in $80 \%$ yield. ${ }^{1} \mathrm{H}$ NMR $\left(400 \mathrm{MHz}, \mathrm{CDCl}_{3}, \delta\right): 8.55(\mathrm{~d}, J=8.5 \mathrm{~Hz}, 6 \mathrm{H}), 7.67$ $(\mathrm{d}, J=8.5 \mathrm{~Hz}, 6 \mathrm{H}$ ). MS(MALDI-TOF, $m / z)$ : calcd. for $\mathrm{C}_{21} \mathrm{H}_{12} \mathrm{Br}_{3} \mathrm{~N}_{3}, 545.8634$, found $545.8658[\mathrm{M}+\mathrm{H}]^{+}$.

Synthesis of compound 2-2

To a $500 \mathrm{~mL}$ two-necked round bottom flask containing paradibromobenzene (16.8 g, $71.8 \mathrm{mmol})$, carbazole $(8.01 \mathrm{~g}, 47.9 \mathrm{mmol})$, 1,10-phenathroline $(0.86 \mathrm{~g}, 4.79 \mathrm{mmol})$, copper(I) chloride( $0.474 \mathrm{~g}, 4.79$ $\mathrm{mmol})$, potassium carbonate(19.85 g, $143.6 \mathrm{mmol}), 150 \mathrm{~mL}$ of ortho-xylene was added with stirring. The reaction mixture was heated at $150^{\circ} \mathrm{C}$ for $48 \mathrm{~h}$ with nitrogen gas protection. The mixture was diluted with hydrochloric acid and extracted with ethyl acetate. The crude product was purified by column chromatography to afford a white crystal $11.13 \mathrm{~g}$ in yield $72 \%$. ${ }^{1} \mathrm{H}$ NMR $\left(400 \mathrm{MHz}, \mathrm{CDCl}_{3}, \delta\right): 8.07-8.05(\mathrm{~m}, 2 \mathrm{H}), 7.65-7.62(\mathrm{~m}, 2 \mathrm{H}), 7.39-7.28(\mathrm{~m}, 6 \mathrm{H})$, 7.24-7.20 (m, 2H).

Synthesis of compound 2-3

To a $200 \mathrm{~mL}$ two-necked round bottom flask containing 2-2 (11.13 g,
$34.67 \mathrm{mmol})$ in $150 \mathrm{~mL}$ dry THF, $2.4 \mathrm{M} n$-BuLi in hexane (10 mL, $24 \mathrm{mmol})$ was added dropwise at $-78^{\circ} \mathrm{C}$ under $\mathrm{N}_{2}$ protection. After stirring for $1.5 \mathrm{hr}$ with the temperature below $-70^{\circ} \mathrm{C}, \mathrm{B}(\mathrm{OMe})_{3}(8 \mathrm{~mL}, 71.8 \mathrm{mmol})$ was added dropwise into the reaction mixture. The solution mixture was allowed to stir overnight and slowly warmed to ambient temperature. Thereafter, the solution was quenched with water and extracted using ethyl acetate. The combined organic layer was washed with saturated $\mathrm{NaCl}_{(\text {aa) }}$ and dried over $\mathrm{Na}_{2} \mathrm{SO}_{4}$. Thus, it was concentrated and purified using column chromatography to obtain a white solid $8.46 \mathrm{~g}$ in $85 \%$ yield which was directly used in the next step.

Synthesis of compound 2-4

Compound 2-3 (8.46 g, $29.45 \mathrm{mmol})$, diethyl 2,5-dibromoterephthalate $(22.4 \mathrm{~g}, 58.9 \mathrm{mmol})$, palladium (II) acetate $(65 \mathrm{mg})$, triphenylphosphine $(0.12$ g), $4 \mathrm{M}$ potassium carbonate $(15 \mathrm{~mL})$, ethanol $(50 \mathrm{~mL})$ and toluene $(250 \mathrm{~mL})$ were added to a $500 \mathrm{~mL}$ two-necked round bottom flask and stirred. The reaction mixture was heated at $45^{\circ} \mathrm{C}$ with nitrogen protection for $24 \mathrm{~h}$. After cooling down to room temperature, the reaction mixture was quenched with water and acidified by $6 \mathrm{M} \mathrm{HCl}(3 \mathrm{~mL})$. Thereafter, it was extracted with 3 portions of ethyl acetate and then dried over sodium sulphate. Thus, purification of residue was carried out via column chromatography to afford a white solid $5.1 \mathrm{~g}$ in $32 \%$ yield. ${ }^{1} \mathrm{H}$ NMR $\left(400 \mathrm{MHz}, \mathrm{CDCl}_{3}, \delta\right): 8.25-8.14(\mathrm{~m}, 3 \mathrm{H}), 7.97-7.84(\mathrm{~m}$, $1 \mathrm{H}), 7.53-7.68(\mathrm{~m}, 4 \mathrm{H}), 7.52-7.42(\mathrm{~m}, 4 \mathrm{H}), 7.36-7.28(\mathrm{~m}, 2 \mathrm{H}), 4.47(\mathrm{q}, J=7.2$ $\mathrm{Hz}, 2 \mathrm{H}), 4.23$ (q, $J=7.2 \mathrm{~Hz}, 2 \mathrm{H}), 1.46(\mathrm{t}, \mathrm{J}=7.2 \mathrm{~Hz}, 3 \mathrm{H}), 1.59$ (t, $J=7.2 \mathrm{~Hz}$, 3H). MS(MALDI-TOF, $m / z)$ : found $542.0964[\mathrm{M}+\mathrm{H}]^{+}$.

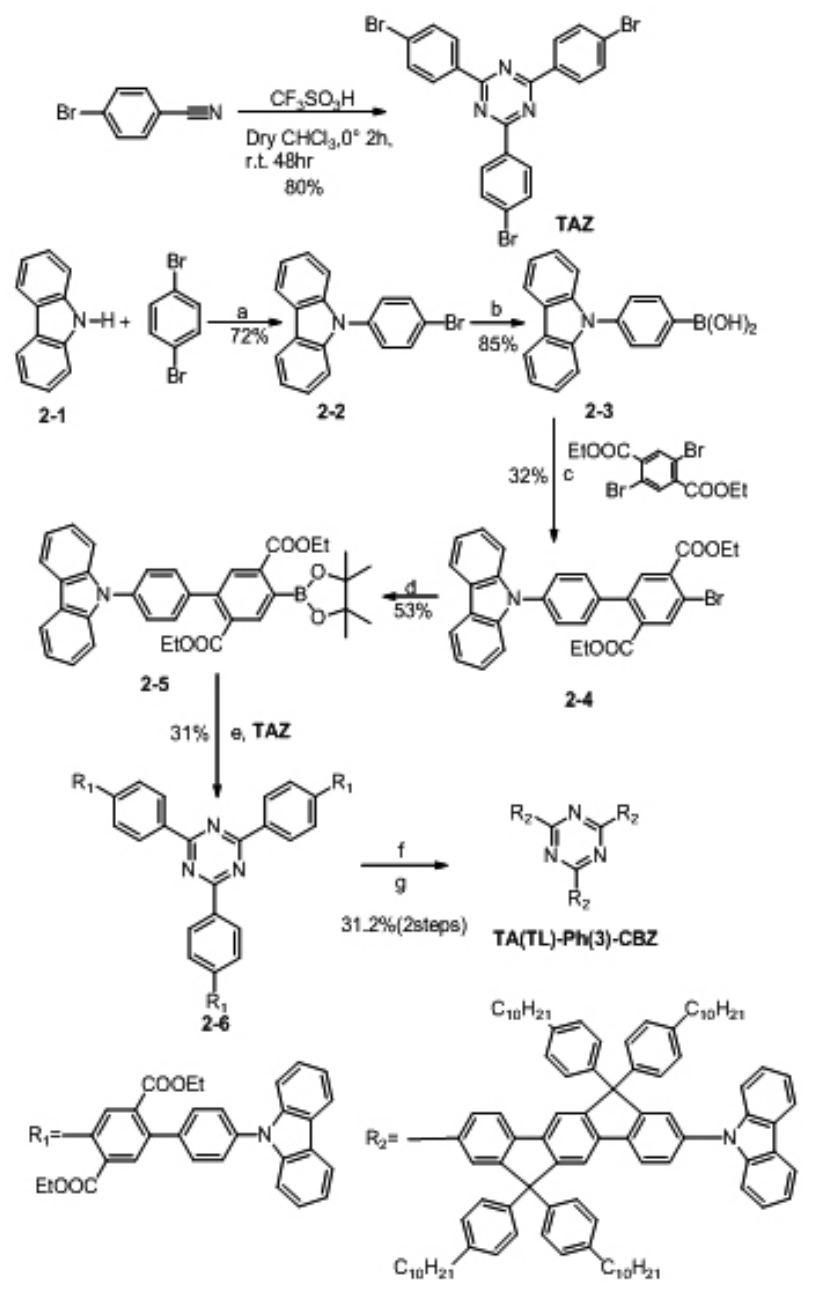

Scheme 1. Synthetic route of TA(TL)-Ph(3)-CBZ. Reagent and conditions: (a) $\mathrm{CuCl}, 1,10$-phenathroline, $\mathrm{K}_{2} \mathrm{CO}$, o-xylene, $150^{\circ} \mathrm{C}, 48 \mathrm{~h}$; (b) 1: n-BuLi, dry THF, $-78^{\circ} \mathrm{C} ; 2: \mathrm{B}(\mathrm{OMe})_{3},-78^{\circ} \mathrm{C}$ to room temperature, overnight. (c) $\mathrm{Pd}(\mathrm{OAc})_{2}, \mathrm{PPh}_{3}, 4 \mathrm{M} \mathrm{K} \mathrm{CO}_{3}, \mathrm{H}_{2} \mathrm{O} /$ Ethanol/Toluene, $45^{\circ} \mathrm{C}, 36 \mathrm{~h}$; (d) $\mathrm{PdCl}_{2}$ (dppf), bis(pinacolato)diboron, $\mathrm{KOAc}, 1,4$-dioxane, $80^{\circ} \mathrm{C}$ (e) $\mathrm{Pd}(\mathrm{OAc})_{2}$, $\mathrm{PPh}_{3}, 4 \mathrm{M} \mathrm{K} \mathrm{CO}_{3}, \mathrm{H}_{2} \mathrm{O} /$ Ethanol/Toluene, $80^{\circ} \mathrm{C}$, reflux, $36 \mathrm{~h}$; (f) 1 -bromo4-decylbenezene, $n$-BuLi, THF, $-78^{\circ} \mathrm{C}, 1.5 \mathrm{~h}$, then r.t. for $24 \mathrm{~h}$; (g) $\mathrm{CF}_{3} \mathrm{SO}_{3} \mathrm{H}$ dissolved in $\mathrm{THF} / \mathrm{CH}_{2} \mathrm{Cl}_{2}, 24 \mathrm{~h}$. 
Synthesis of compound 2-5

To a $250 \mathrm{~mL}$ two-necked round bottom flask containing compound 2-4 (5.1 g, $9.43 \mathrm{mmol})$, bis(pinacolato)-diboron $(4.78 \mathrm{~g}, 18.8 \mathrm{mmol}), \mathrm{KOAc}(3.7$ $\mathrm{g}, 37.7 \mathrm{mmol})$ and $\mathrm{PdCl}_{2}(\mathrm{dppf})(0.15 \mathrm{~g}, 0.184 \mathrm{mmol}), 1,4$-dioxane $(180 \mathrm{~mL})$ was added with stirring under $\mathrm{N}_{2}$ protection. The reaction mixture was allowed to heat $80^{\circ} \mathrm{C}$ for $24 \mathrm{~h}$. Solvent was removed by rotary evaporator and then the residue was diluted with water. The aqueous solution as extracted using dichloromethane. The organic layer was combined and dried over $\mathrm{Na}_{2} \mathrm{SO}_{4}$. The crude product was purified via column chromatography to afford a light yellow powder of $2.94 \mathrm{~g}$ with $53 \%$ yield. ${ }^{1} \mathrm{H}$ NMR $\left(400 \mathrm{MHz}, \mathrm{CDCl}_{3}, \delta\right): 8.13(\mathrm{~d}, J$ $=7.7 \mathrm{~Hz}, 2 \mathrm{H}), 8.04(\mathrm{~d}, 16 \mathrm{~Hz}, 2 \mathrm{H}), 7.57(\mathrm{~m}, 4 \mathrm{H}), 7.43(\mathrm{~m}, 4 \mathrm{H}), 7.28(\mathrm{~m}, 2 \mathrm{H})$, $4.44(\mathrm{q}, J=7.2 \mathrm{~Hz}, 2 \mathrm{H}), 4.19(\mathrm{q}, J=7.2 \mathrm{~Hz}, 2 \mathrm{H}), 1.55(\mathrm{~m}, 12 \mathrm{H}), 1.40(\mathrm{t}, J=7.1$ $\mathrm{Hz}, 3 \mathrm{H}), 1.09(\mathrm{t}, J=7.1 \mathrm{~Hz}, 3 \mathrm{H}) .{ }^{13} \mathrm{C}$ NMR $\left(100 \mathrm{MHz}, \mathrm{CDCl}_{3}, \delta\right): 168.3,167.3$, $142.1,140.8,139.8,137.2,136.6,137.2,136.6,134.1,134.0,130.6,130.0$, $126.7,126.1,123.5,120.5,120.2,109.8,84.5,75.0,67.1,61.7$ (d), 25.0, 24.9, 24.6. MS(MALDI-TOF, $m / z$ ): found $589.2680[\mathrm{M}+\mathrm{H}]^{+}$.

Synthesis of compound 2-6

Compound 2-5 (2.94 g, $4.99 \mathrm{mmol})$, TAZ (0.68 g, $1.25 \mathrm{mmol})$, palladium (II) acetate $(60 \mathrm{mg})$, triphenylphosphine $(0.66 \mathrm{~g}, 2.5 \mathrm{mmol}), 4 \mathrm{M}$ potassium carbonate $(5 \mathrm{~mL})$, ethanol $(40 \mathrm{~mL})$ and toluene $(50 \mathrm{~mL})$ were added to a 250 $\mathrm{mL}$ two-necked round bottom flask. The reaction mixture was refluxed at $80^{\circ} \mathrm{C}$ with nitrogen protection for $36 \mathrm{hr}$. After cooling down to room temperature, the reaction mixture was quenched with water and acidified by $6 \mathrm{M} \mathrm{HCl}(3$ $\mathrm{mL}$ ). Thereafter, it was extracted with 3 portions of ethyl acetate and then dried over sodium sulphate. Thus, purification of residue was carried out via column chromatography to afford a light yellow crystal of $659 \mathrm{mg}$ in yield $31 \% .{ }^{1} \mathrm{H}$ NMR (400MHz, $\left.\mathrm{CDCl}_{3}, \delta\right): 9.00(\mathrm{~d}, J=8.2 \mathrm{~Hz}, 6 \mathrm{H}), 8.16(\mathrm{~m}, 12 \mathrm{H}), 7.74(\mathrm{~m}$, $18 \mathrm{H}), 7.53(\mathrm{~m}, 12 \mathrm{H}), 7.37(\mathrm{t}, J=7.2 \mathrm{~Hz}, 6 \mathrm{H}), 4.30(\mathrm{~m}, 12 \mathrm{H}), 1.20(\mathrm{~m}, 18 \mathrm{H}) .{ }^{13} \mathrm{C}$ NMR (100MHz, $\left.\mathrm{CDCl}_{3}, \delta\right): 171.5,167.8$ (d), 144.6, 141.0, 140.8, 139.3, 137.4, 135.7, 133.7 (d), 132.2 (d), 130.1, 129.0 (d), 126.8, 126.1, 123.6, 109.8, 61.7 (d), 14.0. MS(MALDI-TOF, $m / z)$ : found $1693.6163[\mathrm{M}+\mathrm{H}]^{+}$.

Synthesis of TA(TL)-Ph(3)-CBZ

To a dried $250 \mathrm{~mL}$ two-necked round bottom flask containing compound 2-6 (659 mg, $0.389 \mathrm{mmol}), 1$-bromo-4-decylbenzene (3.47 g, $11.67 \mathrm{mmol}$ ) and anhydrous THF $(40 \mathrm{~mL})$ with stirring and $\mathrm{N}_{2}$ protection at $-78^{\circ} \mathrm{C}, 2.5 \mathrm{M} n-\mathrm{BuLi}$ $(3.6 \mathrm{~mL}, 9.0 \mathrm{mmol}$ )was added dropwise over $20 \mathrm{~min}$. The reaction solution was continued to stir for $2 \mathrm{hr}$ with the temperature lower than $-70^{\circ} \mathrm{C}$ then warmed overnight under ambient temperature and $\mathrm{N}_{2}$ protection. The mixture was then quenched with hydrochloric acid at $0^{\circ} \mathrm{C}$ and extracted using three portions of ethyl acetate. The organic layers were combined, washed with brine and dried over $\mathrm{Na}_{2} \mathrm{SO}_{4}$. A sticky yellow oil was obtained after concentration in vacuo and then directly used in the next step. To the yellow oil obtained in the previous step, $40 \mathrm{~mL}$ dichloromethane was added followed by trifluoromethanesulfonic $\operatorname{acid}(0.15 \mathrm{M}, 10 \mathrm{~mL})$ in $\mathrm{CH}_{2} \mathrm{Cl}_{2} / \mathrm{THF}(100 / 1)$. The reaction mixture was continued to stir for $24 \mathrm{hr}$ at room temperature with $\mathrm{N}_{2}$ protection. The solution mixture was quenched with water and its organic layer was extracted with two portions of DCM. The organic layers were combined, washed with $\mathrm{H}_{2} \mathrm{O}$ and dried over $\mathrm{Na}_{2} \mathrm{SO}_{4}$. The solution was then concentrated by rotary evaporator. Purification of crude product was carried out by column chromatography with and obtained yellow solid ( $477 \mathrm{mg}, 0.124 \mathrm{mmol}$ ) with the total percentage yield (2 steps) of $31.2 \% .{ }^{1} \mathrm{H}$ NMR $\left(400 \mathrm{MHz}, \mathrm{CDCl}_{3}, \delta\right): 8.74(\mathrm{~m}, 6 \mathrm{H}), 8.15(\mathrm{~d}, J=$ $8 \mathrm{H}, 6 \mathrm{H}), 8.0-7.8(\mathrm{~m}, 12 \mathrm{H}), 7.66(\mathrm{~m}, 3 \mathrm{H}), 7.58(\mathrm{~d}, J=8 \mathrm{~Hz}, 3 \mathrm{H}), 7.43(\mathrm{~m}, 15 \mathrm{H})$, $7.30(\mathrm{~m}, 27 \mathrm{H}), 7.22-7.03(\mathrm{~m}, 27 \mathrm{H}), 2.59(\mathrm{q}, J=8 \mathrm{~Hz}, 8 \mathrm{H}), 1.62(\mathrm{~d}, J=4.5 \mathrm{~Hz}$, $21 \mathrm{H}), 1.26(\mathrm{~m}, 168 \mathrm{H}), 0.87(\mathrm{q}, J=6.7 \mathrm{~Hz}, 36 \mathrm{H}) .{ }^{13} \mathrm{C} \mathrm{NMR}\left(100 \mathrm{MHz}, \mathrm{CDCl}_{3}\right.$,

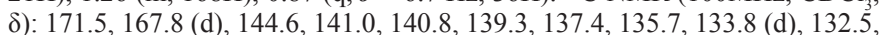
132.2 (d), 131.0, 130.1, 129.0 (d), 128.9, 126.8, 126.1, 123.6, 120.5, 120.2, 109.8, 77.2 (t), 68.2, 61.7 (d), 38.8, 30.5, 29.8, 29.0, 23.8, 23.1, 14.2, 14.0, 11.1. MS(MALDI-TOF, $m / z$ ): found 3929.7550 , requires $3929.7516[\mathrm{M}+\mathrm{H}]^{+}$.

\section{RESULT AND DISCUSSION}

\section{Synthesis}

Theacceptorcorewas synthesized with theyield of $80 \%$ bycyclotrimerization of para-bromobenzonitrile catalyzed by trifluoromethanesulfonic acid. The compound 2-2 was efficiently synthesized by Ullmann-type condensation which possessed a high selectivity in giving the mono-substituted, even if the addition of 2 to 6 equivalent para-dibromobenzene. Hence, a borolyation was carried out to give the intermediation compound $\mathbf{2 - 3}$ which is the precursor used in synthesizing the compound 2-4 via palladium-catalyzed Suzuki coupling. Thereafter, a borylation of compound 2-4 was carried out to give the precursor compound 2-5 in the next step. A three-fold Suzuki coupling was conducted between compound 2-5 and TAZ to afford compound 2-6 which was converted to $\mathbf{T A}(\mathbf{T L})-\mathbf{P h}(3)-\mathbf{C B Z}$ via nucleophilic attack 1-bromo-4-decylbenzene and ring-closure catalyzed by trifluoromethanesulfonic acid (Scheme1).

Linear optical properties

Thermal properties of the synthesized compound TA(TL)-Ph(3)-CBZ were characterized by thermogravimetric analysis. TA(TL)-Ph(3)-CBZ exhibits similar decomposition temperature with the synthesized prototypes of MPA active oligomers N(TL)-Ph(3)-CBZ, TA(TL)-Ph(3)-NPh and (L)Ph(3)-NPh.
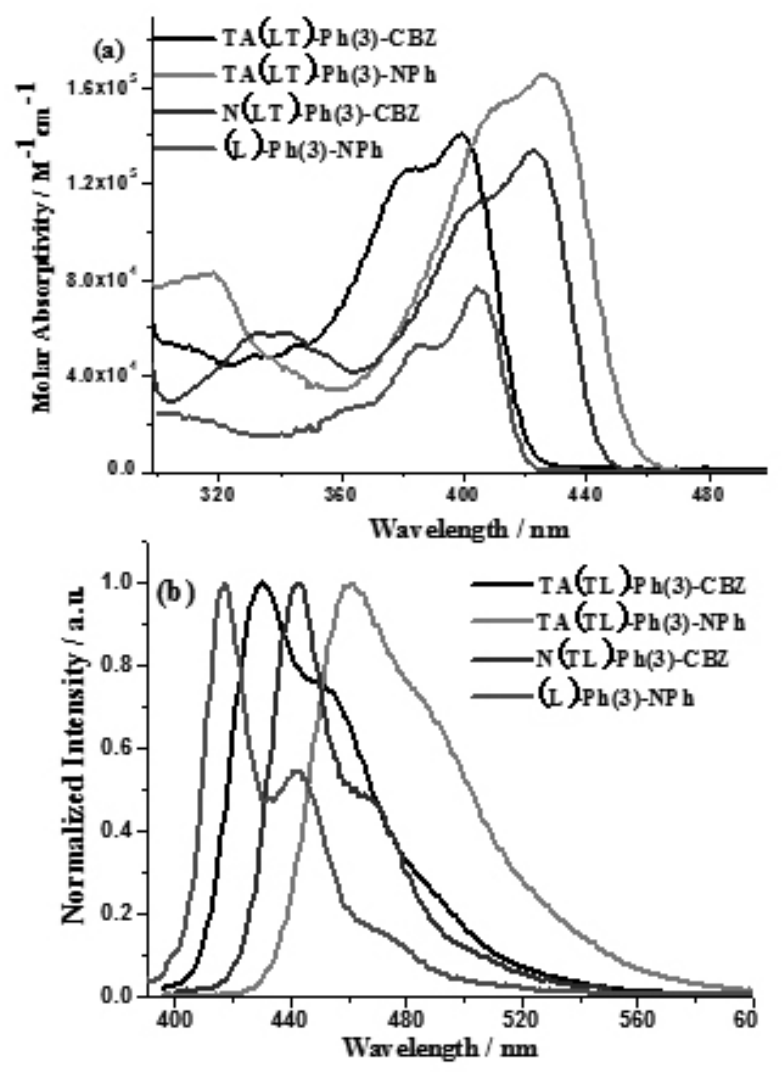

Figure 5. UV-vis absorption and fluorescence spectra of star-shaped oligomers in toluene.

The optical properties of newly synthesized compound TA(TL)-Ph(3)CBZ were achieved by using UV-Visible and fluorescence spectroscopies. TA(TL)-Ph(3)-CBZ has good solubility in either chloroform or toluene but very insoluble in DMF unless heating, which is not suitable to characterize its linear optical properties in DMF. The linear optical properties were listed as well as the thermal property in Table-1.The UV-Visible and fluorescence spectra are shown in Fig.5 and Fig.6.

As shown on the optical spectra Fig.5 and Fig.6, TA(TL)-Ph(3)-CBZ exhibited a blue shift from the others, which suggests the intramolecular charge transfer is significantly differ from the prototypes. Absorption below the $320 \mathrm{~nm}$ region represents a higher energy acquisition responsible for the transition from $n$ to $\pi^{*}$ of the lone pair electron of carbazole moiety. More intensive absorption between $380 \mathrm{~nm}$ and $420 \mathrm{~nm}$ depicting the transition of $\pi$ to $\pi^{*}$ of the $\pi$-conjugated bridges.

The result suggests the carbazole moiety acts differently in terms of electron inductive effect that means the $N$-substituted carbazole may largely weakens its electron withdrawing effect when compared with TA(TL)-Ph(3)-NPh. The observed derivation can be rationalized by the lower degree of electric polarization of the $\pi$-conjugated system of electron accepting 1,3,5-triazine core end-capped with carbazole.

TA(TL)-Ph(3)-CBZ has a blue shift on fluorescence spectrum upon excitation in chloroform when compared with the excitation in toluene, which suggests solvatochromic effect takes place in emission spectrum conducted using chloroform. 


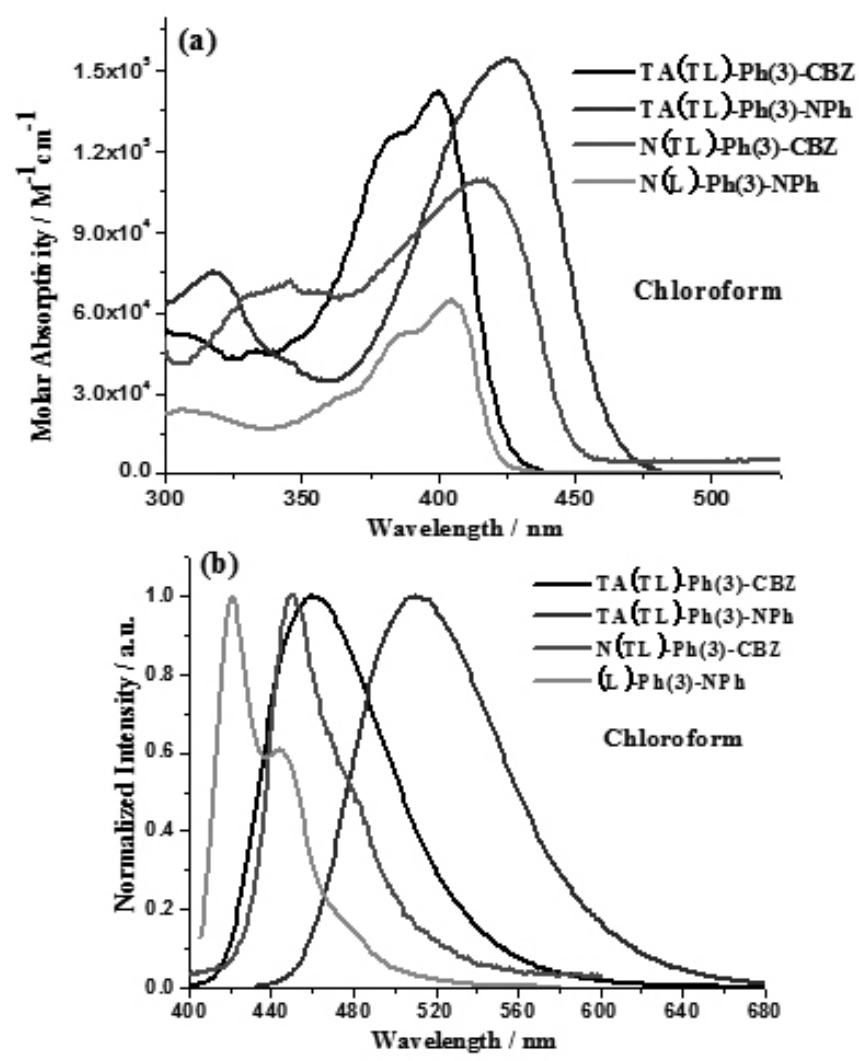

Figure 6. UV-vis absorption and fluorescence spectra of star-shaped oligomers in Chloroform.

Table 1: Summary of linear optical measurements of star-shaped oligomers.

\begin{tabular}{|c|c|c|c|c|}
\hline Compounds & $\begin{array}{c}(L)- \\
\text { Ph(3)- } \\
\text { NPh }\end{array}$ & $\begin{array}{c}\text { N(TL)- } \\
\text { Ph(3)-NPh }\end{array}$ & $\begin{array}{c}\text { TA(TL)- } \\
\text { Ph(3)-NPh }\end{array}$ & $\begin{array}{c}\text { TA(TL)- } \\
\text { Ph(3)- } \\
\text { CBZ }\end{array}$ \\
\hline$\lambda^{a} \quad / \mathrm{nm}(\varepsilon)$ & $405(0.77)$ & $429(1.74)$ & $427(1.65)$ & $399(1.40)$ \\
\hline$\lambda^{a} / \mathrm{nm}$ & 417,443 & 443 & 461 & 430 \\
\hline$\lambda^{b} \quad / \mathrm{nm}(\varepsilon)$ & $404(0.64)$ & $423(1.35)$ & $426(1.54)$ & $399(1.42)$ \\
\hline$\lambda^{b} / \mathrm{nm}$ & 421,444 & 451 & 510 & 459 \\
\hline$\lambda^{\mathrm{d}} / \mathrm{nm}$ & 403 & 427 & 427 & Insoluble \\
\hline$\lambda^{d} / \mathrm{nm}$ & 428 & 457 & 591 & Insoluble \\
\hline$\Phi^{a}$ & $0.85^{c}$ & $0.86^{c}$ & $0.90^{c}$ & $0.87^{c}$ \\
\hline $\mathrm{T}_{d}{ }^{e} /{ }^{\circ} \mathrm{C}$ & 435 & 463 & 426 & 448 \\
\hline
\end{tabular}

${ }^{a}$ average of three independent measurements using toluene, molarabsorption coefficient $\varepsilon\left(\times 10^{5} \times \mathrm{M}^{-1} \cdot \mathrm{cm}^{-1}\right),{ }^{b}$ average of three independent measurements using chloroform, molarabsorption coefficientse $\left(\times 10^{5} \times \mathrm{M}^{-1} \cdot \mathrm{cm}^{-1}\right)$. ${ }^{c}$ using Norharman $\left(\Phi_{330 \sim 390}=0.58\right)$ as standard. daverage of two independent measurements using DMF. ${ }^{e}$ determined by TGA analyzer with a heating rate of $20^{\circ} \mathrm{C} / \mathrm{min}$ under nitrogen

Non Linear Optical Properties

Two-photon excited fluorescence will be achieved as to determine the 2PA and 3PA cross-section as well as the frequency up-conversion efficiency when the related instruments are repaired.

\section{CONCLUSION}

In summary, star-shaped ladder-type ter(p-phenylene) compound composed of 1,3,5-triazine core with alkylphenyl group attached $\pi$-conjugated arms end-capped with carbazole was synthesized and characterized for its optical and thermo properties. TA(TL)-Ph(3)-CBZ exhibits a blue shift when compared with other compounds composed of either triazine or triphenyl core with the terminals of diphenylamine. TA(TL)-Ph(3)-CBZ can potentially be employed in the application of blue-light emitting materials with strong emission of blue shifted light.

\section{ACKNOWLEDGEMENTS}

We acknowledge support of this work by the National Science Foundation of China (Grant no.11076017).

\section{REFERENCES}

1. M. M.Goppert, Ann. Physik, 9, 273-295, (1931)

2. W. Kaiser, C. G. Garrett, Phys. Rev. Lett. 7, 229-232, (1961)

3. W. Denk, J. H. Strickler, W. W. Webb, Science. 248, 73, (1990)

4. C. S. Lai, W. Franke, T. F. Gan, Nature. 483, 87-91, (2012)

5. M. L. Drobizhev, N.S. Makarv, S.E. Tillo, T.E. Hughes, A. Rebane, Nature Methods. 8, 393-399, (2011)

6. I. Polyzos, G. Tsigaridas, M. Fakis, Chem. Phys. Lett. 369, 264-268, (2003)

7. S. M. Zhang, B. Zhu, S. F. Zhou, S. Q. Xu, J. R. Qiu, Opt Express.15(11), 6883-6888, (2007)

8. H. B. Sun, S. Kawata, Adv. Polym. Sci, 170, 169-273, (2004)

9. C. W. J. Spangler, Material Chemistry. 398, 2013, (1999)

10. W. W. Fisher, W. P. Paratridge, Photochem. Photobiol. 66, 141, (1997)

11. P. Hanczyc, M. Samoc, B. Norden, Nat. Photonics. 7, 969-972, (2013)

12. G. Ramakrishna, T. Goodson, J. Phys. Chem. A. 111, 993, (2007)

13. K. A. L. Nguyen, J. E. Rogers, J. E. Slagle, P. N. L, J. Phys. Chem. A. 110, 13172, (2006)

14. M. Drobizhev, Y. Stepanenko, Y. Dzenis, J. Am. Chem. Soc. 2004, 126, 15352-15353, (2004)

15. Y. Yi, L. Zhu, Z. Shuai, Macromol. Theory Siuml. 17, 12, (2008)

16. R. Kannan, G. S. He, L. Yuan, F. Xu, Chem. Mater. 13, 1896-1904, (2001)

17. A. G. Dillard, J. C. Bhatt, R. Kannan, L. Yuan, Chem. Mater. 10, 18631874, (1998)

18. C. Delacourt, Chem. Mater, 16, 93-99, (2004)

19. M. Drobizhev, Y. Stepanenko, Y. Dzenis, A. Karotki, J. Am. Chem. Soc. 126, 15352-15353, (2004)

20. L. Guo, K. F. Li, M. S. K. W. Wong, Chem. Commun. 49, 3597, (2013)

21. P. L.Wu, X. J. Feng, M. S. Wong, J. Am. Chem. Soc. 131, 886-887, (2009) 